\title{
Shared decision-making for biologic treatment of autoimmune disease: influence on adherence, persistence, satisfaction, and health care costs
}

This article was published in the following Dove Press journal:

Patient Preference and Adherence

18 May 2017

Number of times this article has been viewed

\author{
Jennifer H Lofland' \\ Phaedra T Johnson ${ }^{2}$ \\ Mike P Ingham ${ }^{3}$ \\ Sarah C Rosemas ${ }^{2}$ \\ John CWhite ${ }^{2}$ \\ Lorie Ellis ${ }^{3}$
}

'Janssen Global Commercial Strategic Organization - Immunology, Raritan, NJ, ${ }^{2}$ Health Economics and Outcomes Research, Optum Inc., Eden Prairie, $\mathrm{MN},{ }^{3} \mathrm{Health}$ Economics and

Outcomes Research, Janssen Scientific Affairs, LLC, Raritan, NJ, USA
Correspondence: Phaedra T Johnson Health Economics and Outcomes Research, Optum Inc., I I000 Optum Circle, Eden Prairie, MN 55344, USA Tel +l 9522057737

Email phaedra.johnson@optum.com
Background: Shared decision-making (SDM), a process whereby physicians and patients collaborate to select interventions, is not well understood for biologic treatment of autoimmune conditions.

Methods: This was a cross-sectional survey of adults initiating treatment for Crohn's disease or ulcerative colitis (inflammatory bowel disease, IBD) or psoriatic arthritis or rheumatoid arthritis (RA/PA). Survey data were linked to administrative claims for 6 months before (baseline) and after (follow-up) therapy initiation. Measures included the Shared Decision Making Questionnaire, Patient Activation Measure (PAM), Morisky Medication Adherence Scale (MMAS), general health, and treatment satisfaction. Claims-based Quan-Charlson comorbidity scores, persistence, medication possession ratio (MPR), and health care costs were examined. Patients were compared by participation (SDM) and nonparticipation (non-SDM) in SDM.

Results: Among 453 respondents, 357 were eligible, and 306 patients (204 RA/PA and 102 IBD) were included in all analyses. Overall $(n=357)$, SDM participants $(n=120)$ were more often females ( $75.0 \%$ vs $62.5 \%, P=0.018)$, had lower health status ( 48.0 vs $55.4, P=0.005)$, and higher Quan-Charlson scores ( 1.0 vs $0.7, P=0.035)$ than non-SDM ( $\mathrm{n}=237)$ participants. Lower MMAS scores (SDM 0.17 vs non-SDM $0.41 ; P<0.05$ ) indicated greater likelihood of adherence; SDM participants also reported higher satisfaction with medication and had greater activation (PAM: SDM vs non-SDM: 66.9 vs 61.6; $P<0.001$ ). Mean MPR did not differ, but persistence was longer among SDM participants (111.2 days vs 102.2 days for non-SDM; $P=0.029$ ). Costs did not differ by SDM status overall, or among patients with RA/PA. The patients with IBD, however, experienced lower $(P=0.003)$ total costs $(\$ 9,404$ for SDM vs $\$ 25,071$ for non-SDM) during follow-up.

Conclusion: This study showed greater likelihood of adherence and satisfaction for patients who engaged in SDM and reduced health care costs among patients with IBD who engaged in SDM. This study provides a basis for defining SDM participation and detecting differences by SDM participation for biologic treatment selection for autoimmune conditions.

Keywords: biologic therapy, autoimmune disease, cross-sectional survey, shared decisionmaking

\section{Introduction}

Shared decision-making (SDM) in medical care is a process whereby physicians and patients, who have a condition with $>1$ acceptable treatment choice, select an intervention that is in accordance with the patients' preferences and values. ${ }^{1}$ The concept of SDM has received increasing interest as the US Section 3406 of the Affordable Care $\mathrm{Act}^{2}$ provides funding for the establishment of standards for certification of patient 
decision aids (PDAs) to help physicians educate patients about their options. ${ }^{3,4}$

Previous research suggests that the potential benefits of SDM for treatment selection may include improved adherence and reduced health care costs; ${ }^{5-7}$ however, this is a relatively new area of research and a correlation between SDM and outcomes has not yet been established. Currently, there is no consensus among the clinical community regarding the components of effective SDM, although SDM patient questionnaires have been developed and validated. ${ }^{8-12}$

Biologic therapies that target specific molecular mechanisms within the immune system have been developed and approved for the treatment of chronic, systemic immune disorders. However, biologics are not frequently used as first-line medications for autoimmune conditions, and the process of deciding to advance treatment to biologics requires consideration of many benefits, risks, lifestyle and economic factors, and alternatives, unique to an individual patient's condition and preferences. ${ }^{13-15}$ The large variety of available biologics provides physicians and patients the option of selecting an appropriate therapy based on patient preferences, including mechanism of action, frequency of administration, duration of response, and costs of therapy.

Previous observational studies have explored patients' and providers' preferences regarding treatment selection in autoimmune disorders, such as rheumatoid or psoriatic arthritis (RA/PA) and inflammatory bowel disease (IBD), with a focus on the SDM process ${ }^{16,17}$ and better understanding of patient perspective regarding SDM. ${ }^{18}$ Studies have also shown that the majority of patients would prefer an SDM approach ${ }^{17,19-21}$ and that SDM results in increased satisfaction ${ }^{22}$ with treatment of autoimmune diseases.

The implementation and study of patient-centered approaches to treatment of complex, chronic immune conditions with biologic therapy represent a growing area of importance in health care..$^{5,16,21,23-25}$ However, to our knowledge, research has not been done to date to examine the impact of SDM on specific outcomes such as medication adherence, persistence, and overall health care costs particularly with respect to selection of biologic treatment for autoimmune disorders (including ulcerative colitis and Crohn's disease [IBD] or RA/PA). In an effort to examine the impact of SDM for biologic treatment selection on future outcomes for patients with autoimmune conditions, we examined 1) the SDM process for biologic treatment selection, 2) patient characteristics and other factors (health status, activation, adherence, and satisfaction) associated with SDM and nonSDM participation, and 3) the relationship between SDM and medication adherence and persistence, and health care costs in the 6 months following biologic initiation for patients having IBD or RA/PA.

\section{Methods \\ Study design}

This was an observational administrative claims-linked survey study of adult commercial enrollees of large US-managed care plans who newly initiated biologic therapy for IBD or RA/PA. Study subjects were identified using medical claims, pharmacy claims, and enrollment data from a proprietary research claims database - the Optum ${ }^{\mathrm{TM}}$ Research Database (ORD). The ORD includes $\sim 14$ million enrollees in commercial plans and 500,000 enrollees in Medicare Advantage with Part D (MAPD) plans annually. This study was approved and overseen by the New England Institutional Review Board (IRB; Newton, MA, USA; study 13-448).

\section{Study sample}

Patients were identified on a rolling basis in the ORD in 7 unique waves between January 29, and October 10, 2014. To be included in the study sample, patients were required to have evidence of new initiation of a biologic therapy, defined as at least 1 pharmacy or medical claim for any of the following agents during the most recent month of data available in the ORD at the time of identification: tocilizumab (Actemra ${ }^{\circledR}$, Genentech); certolizumab pegol $\left(\mathrm{Cimzia}^{\circledR}, \mathrm{UCB}\right.$, Inc.); etanercept (Enbrel ${ }^{\circledR}$, Amgen); adalimumab (Humira ${ }^{\circledR}$, AbbVie, Inc.); anakinra (Kineret ${ }^{\circledR}$, SOBI, Inc.); abatacept (Orencia ${ }^{\circledR}$, Bristol-Myers Squibb); infliximab (Remicade ${ }^{\circledR}$, Janssen Biotech, Inc.); rituximab (Rituxan ${ }^{\circledR}$, Genentech); golimumab (Simponi ${ }^{\circledR} /$ Simponi Aria ${ }^{\circledR}$, Janssen Biotech, Inc.); ustekinumab (Stelara ${ }^{\circledR}$, Janssen Biotech, Inc.); or natalizumab (Tysabri ${ }^{\circledR}$, Biogen). The index date was defined as the date of the first claim for the biologic agent.

In addition, patients were required to have 1) at least 2 medical claims with the following International Classification of Diseases, 9th Revision, Clinical Modification (ICD-9-CM) codes occurring at least 30 days apart, within 6 months before the drug index date (for IBD: Crohn's disease, 555.xx; ulcerative colitis, 556.xx; or RA/PA: RA, 714.0x-714.2x; PA, 696.0x); 2) be aged $\geq 18$ years as of the index date; and 3) be continuously enrolled in the health plan for the 6 months prior to and 6 months after the drug index date.

Patients were excluded if there was evidence of receipt of any of the biologic agents during the preindex (baseline) period; evidence of initiating more than one of the biologic 
agents on the drug index date; or if they received a biologic not approved for the identified diagnosis.

\section{Survey recruitment}

For each wave, identified patients were contacted for study participation by mail $\sim 8$ weeks after the index date. The study mailing included an invitation letter, the cross-sectional survey instrument, and a prepaid envelope. Following completion of all waves of survey fielding, patients' pharmacy and medical claims data for the 6 months prior to the index date (baseline period) and the 6 months following the index date (6-month postindex period) were extracted from the ORD and linked to the cross-sectional survey data for analysis. Patients' clinical characteristics (disease history and comorbid conditions) were assessed during the baseline period and outcomes (medication compliance and persistence), and health care costs were assessed for the 6-month postindex period. As approved by the New England IRB, an informed consent statement was included in the mailed invitation to participate, and consent was implied upon return of the completed survey.

\section{Survey measures}

\section{Demographic and clinical characteristics}

Patients' demographic data (age, gender, and race/ethnicity) and clinical characteristics (autoimmune diagnoses, years since diagnosis, and current and previous biologic medications used) were collected on the survey.

\section{SDM participation and biologic treatment selection}

The 9-item Shared Decision Making Questionnaire (SDM-Q-9) ${ }^{8}$ was used to assess patients' participation in SDM for biologic therapy selection. SDM scores were transformed on a scale of $0-100$, with the higher score indicating greater participation in SDM. The total SDM-Q-9 score was used to assign patients to 2 analytic cohorts: SDM and nonSDM participants. Respondents who answered "strongly agree" or "completely agree" to all 9 questions, which equates to a transformed score of $\geq 80$, were assigned to the SDM cohort. Respondents who did not meet these criteria were assigned to the non-SDM cohort. In addition, patients were asked several questions regarding the biologic therapyrelated discussions that they had with their prescribing doctor prior to therapy initiation, including 1) who initiated the conversation, 2) how many visits included a therapy discussion and over how many months, 3) how many options were discussed, including brand options, 4) which attributes were discussed and at what level of detail, 5) what mode of administration was recommended by their physician, and 6) if they requested a mode of administration. Questions about patients' treatment considerations (eg, whether they think more about current or future health state) as well as decisions (eg, whether they make the final decision, whether the physician makes the final decision, and whether they share the responsibility) were also asked.

\section{Patient-reported outcome measures}

Patients also completed a general self-rated health (GSRH) status scale, ${ }^{26}$ a single item consisting of a 5-point Likert scale ranging from excellent to poor, transformed on a 0-100 scale, with a higher score indicating greater health status. In addition, the survey included the Patient Activation Measure (PAM), which assessed patient knowledge, skill, and confidence for self-management. ${ }^{27}$ This scale consists of 13 items with a 4-point Likert scale ranging from strongly disagree to strongly agree, with a not-applicable response option. Participants were categorized into 1 of 4 stages of activation, based upon a score ranging from 0 to 100 , with higher scores representing greater activation. Self-reported adherence was measured using the Morisky Medication Adherence Scale (MMAS), ${ }^{28-30}$ which consisted of 4 items with a dichotomous yes/no response to each question. Summary scores ranged from 0 to 4 : with 0 indicating high adherence and 3-4 indicating low adherence. The survey also asked questions about current biologic treatment attributes regarding efficacy, method of administration, how quickly the treatment worked to reduce symptoms, and overall satisfaction, using a 5-point Likert scale ranging from not-at-all satisfied to extremely satisfied.

\section{Administrative claims measures}

Patients' baseline medical claims were used to calculate a Quan-Charlson comorbidity score. ${ }^{31}$ During the 6-month follow-up period, patients' persistence with index medication (persistent days $=$ the number of days from index date to discontinuation [a gap in therapy of $\geq 60$ days]), and gaps in therapy (being without medication following the run out date [run out date $=$ fill date + days' supply -1$]$ ) were assessed using pharmacy and medical claims. Adherence to index therapy was measured using a medication possession ratio (MPR). The MPR was calculated by summing the number of days supplied for the index medication for all but the last fill in the observation period, divided by the number of days between the first and the last refill in the observation period. An MPR $>1.0$ was capped at 1.0. For medications filled through the pharmacy benefit, the days' supply was used to determine the run out date 
for the fill. For medications filled through the pharmacy, the days' supply (derived from the pharmacy record) was rounded to the nearest 14-day value (eg, 58 days will be rounded to $56)$. For cases when there was an invalid $(\leq 0)$ days' supply on the pharmacy claim and for medications administered by physicians (as days' supply information are not available for medical claims), a presumed days' supply was applied, based on guidelines per the product label.

Patients' pharmacy and medical claims during the 6-month postindex period were used to evaluate patient health care costs. All-cause health care costs, which were computed as the combined health plan and patient paid amounts in the postindex period, were calculated for the following categories: total costs, medical costs, pharmacy costs, ambulatory costs, emergency services costs, inpatient costs, and other costs. Costs were grouped as SDM vs non-SDM status within each therapeutic area. Costs were adjusted to those of 2014 using the annual medical care component of the Consumer Price Index to reflect inflation between the earliest and latest year of data.

\section{Statistical analysis}

All study variables were analyzed descriptively. Numbers and percentages were provided for dichotomous and polychotomous variables, with mean and standard deviation (SD) presented for continuous measures. Bivariate comparisons of demographic characteristics and outcome measures were conducted, using appropriate tests (eg, Student's $t$-test, Mann-Whitney $U$ test, and Chi-square test) based on the distributions of the measures.

Results were first analyzed based upon SDM vs nonSDM. The 2 cohorts were compared in terms of demographic characteristics, Quan-Charlson comorbidity score, GSRH, PAM, satisfaction, MMAS, persistence, adherence (MPR), and health care costs. In addition, within each sample identified by self-reported disease state - RA/PA or IBD - results were examined for claims-based data: demographic/clinical characteristics, persistence, MPR, and health care costs.

\section{Results \\ Description of study enrollment and final sample}

A total of 1,200 patients were sent a survey across the 7 waves; each wave comprised between 79 and 265 patients. Based on the American Association for Public Opinion Research's (AAPOR) Response Rate \#4 calculation, the overall response rate to the cross-sectional survey was $37.8 \%$, yielding a total of 453 surveys. ${ }^{32}$ After application of additional criteria (Figure 1), the total number of patients included in the analyses was 357 overall. Including the specific therapeutic indications of interest, the final total was 306 patients, with 204 patients having RA/PA (75 SDM and 129 non-SDM participants) and 102 having IBD (33 SDM and 69 non-SDM participants).

\section{Patient characteristics}

Based on SDM-Q-9 total scores among the overall population, a total of 120 patients participated in SDM and 237 patients did not (mean [SD] score: 92.6 [7.8] and 70.8 [17.0], respectively). Demographic and clinical characteristics by SDM status (overall and by therapeutic indication) are presented in Table 1.

Demographic and clinical characteristics did not significantly differ when comparing SDM and non-SDM participants by age, race/ethnicity, or the type of specialty of their prescribing provider (Table 1). When analyzed within therapeutic indications, IBD or RA/PA, no significant differences were observed between SDM and non-SDM patients in any of the baseline demographic or clinical characteristics, with the exception of gender, among RA/PA patients ( $\mathrm{SDM}=82.7 \%$ female vs non-SDM $=68.2 \%$ female; $P=0.032$ ). Overall, patients who participated in SDM, as compared with nonSDM participants, were more likely to be females $(75.0 \%$ vs $62.5 \% ; P=0.018)$ and have lower self-reported health status (mean GSRH score of 48.0 vs $55.4 ; P=0.005$ ). Similarly, SDM participants were more likely than their non-SDM counterparts to have between 1 and 2 comorbid conditions (57.5\% vs $40.9 \% ; P=0.003)$, and overall, had a higher mean Quan-Charlson score (1.0 vs $0.7 ; P=0.035$ ).

The biologic agent initiated by patients did not significantly differ between SDM and non-SDM participants by either the overall or RA/PA and IBD groups, with the exception of rituximab, which was more often used among SDM participants (7.5\%, compared with non-SDM, 2.1\%; $P=0.019)$ and the RA/PA SDM cohort (12.0\%, compared with the RA/PA non-SDM patients, $3.9 \% ; P=0.042)$. The most common index biologics overall were etanercept (31.9\%), adalimumab (28.3\%), infliximab (12.9\%), certolizumab pegol (10.9\%), and golimumab and ustekinumab (both $4.8 \%$ ). The majority of providers among the patients with IBD were gastroenterologists (93.8\% among SDM and $62.3 \%$ among non-SDM patients) and $>80 \%$ of RA/PA patients were treated by rheumatologists.

The majority $(81.8 \%)$ of patients among the entire sample had self-injected administration, rather than intravenous infusion, although there were no significant differences by 


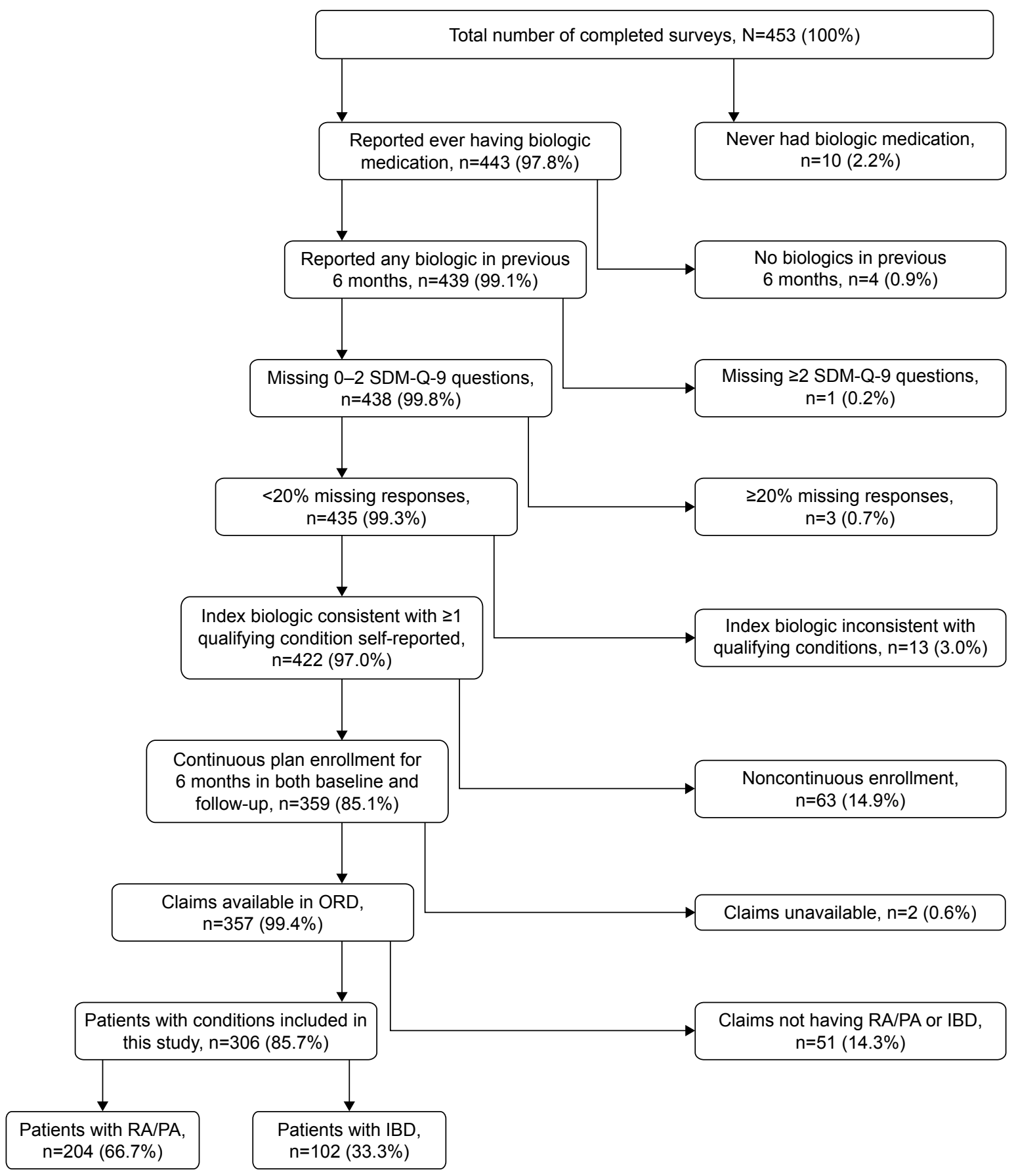

Figure I Study sample selection and attrition.

Abbreviations: IBD, inflammatory bowel disease; ORD, Optum ${ }^{\text {TM }}$ Research Database; PA, psoriatic arthritis; RA, rheumatoid arthritis; SDM, shared decision-making; SDMQ-9, 9-item Shared Decision Making Questionnaire.

SDM status for either the requested mode (survey results) or the received mode (claims results) of administration (not shown). Among RA/PA patients, the non-SDM patients more often $(89.9 \%)$ received self-injected medication than the SDM patients $(77.3 \% ; P=0.023)$; there were no differences by SDM status among IBD patients in the mode requested or received.

\section{Biologic treatment selection}

Among SDM participants, the mean number of treatments discussed with the physician was significantly higher (2.8 vs 2.2; $P<0.05)$, than for the non-SDM cohort. In addition, regarding beliefs about biologic medications, more SDM participants indicated thinking about the impact of a medication on both the present condition and the future than did 
Table I Demographic and clinical characteristics

\begin{tabular}{|c|c|c|c|c|c|c|}
\hline & \multicolumn{2}{|l|}{ Total } & \multicolumn{2}{|l|}{ IBD } & \multicolumn{2}{|l|}{ RA/PA } \\
\hline & $\begin{array}{l}\text { SDM } \\
(n=\mid 20)\end{array}$ & $\begin{array}{l}\text { Non-SDM } \\
(\mathrm{n}=237)\end{array}$ & $\begin{array}{l}\text { SDM } \\
(n=33)\end{array}$ & $\begin{array}{l}\text { Non-SDM } \\
(n=69)\end{array}$ & $\begin{array}{l}\text { SDM } \\
(n=75)\end{array}$ & $\begin{array}{l}\text { Non-SDM } \\
(n=129)\end{array}$ \\
\hline Age (years), mean (SD) & $47.9(11.6)$ & $48.0(12.4)$ & $42.9(11.7)$ & $43.4(12.7)$ & $51.3(10.7)$ & $51.0(11.3)$ \\
\hline Gender: $\mathrm{n}(\%)$ female & $90(75.0)$ & $148(62.5)^{*}$ & $24(72.7)$ & $36(52.2)$ & $62(82.7)$ & $88(68.2)^{*}$ \\
\hline \multicolumn{7}{|l|}{ Race/ethnicity, n (\%) } \\
\hline American Indian or Alaskan Native & $3(2.5)$ & $2(0.9)$ & I (3.0) & $0(0.0)$ & $2(2.7)$ & $2(1.6)$ \\
\hline Asian & $2(1.7)$ & $2(0.9)$ & $0(0.0)$ & $0(0.0)$ & $2(2.7)$ & $2(1.6)$ \\
\hline Black or African-American & $5(4.2)$ & $12(5.1)$ & $0(0.0)$ & $\mathrm{I}(\mathrm{I} .5)$ & $5(6.7)$ & $10(7.8)$ \\
\hline Native Hawaiian or Pacific Islander & $0(0)$ & $0(0)$ & $0(0.0)$ & $0(0.0)$ & $0(0.0)$ & $0(0.0)$ \\
\hline White & $108(90.0)$ & $216(91.9)$ & $31(93.9)$ & $67(97.1)$ & $65(86.7)$ & $113(88.3)$ \\
\hline Other race & $5(4.2)$ & $5(2.1)$ & $2(6.1)$ & I (I.5) & $3(4.0)$ & $3(2.3)$ \\
\hline Hispanic ethnicity (yes) & $8(6.7)$ & $14(5.9)$ & $3(9.1)$ & $0(0.0)^{*}$ & $5(6.7)$ & $10(7.8)$ \\
\hline \multicolumn{7}{|l|}{ Geographic region, n (\%) } \\
\hline Northeast & $\mathrm{I}(0.8)$ & $12(5.1)$ & I (3.0) & $5(7.2)$ & $\mathrm{I}(\mathrm{I} .3)$ & $3(2.3)$ \\
\hline Midwest & $40(33.3)$ & $56(23.6)$ & $12(36.4)$ & $19(27.5)$ & $23(30.7)$ & $30(23.3)$ \\
\hline South & $55(45.8)$ & $120(50.6)$ & $12(36.4)$ & $31(44.9)$ & $38(50.7)$ & $74(57.4)$ \\
\hline West & $24(20.0)$ & $49(20.7)$ & $8(24.2)$ & $14(20.3)$ & $13(17.3)$ & $22(17.0)$ \\
\hline \multicolumn{7}{|l|}{ Autoimmune condition, $\mathrm{n}(\%)^{\mathrm{a}}$} \\
\hline Ulcerative colitis & $13(10.8)$ & $21(8.9)^{*}$ & $13(39.4)$ & $21(30.4)$ & $\mathrm{I}(\mathrm{I} .3)$ & $2(1.6)$ \\
\hline Crohn's disease & $21(17.5)$ & $50(2 \mathrm{I} . \mathrm{I})^{* * * *}$ & $21(63.6)$ & $50(72.5)$ & $0(0.0)$ & $2(1.6)$ \\
\hline Rheumatoid arthritis & $60(50.0)$ & $101(42.6)$ & $0(0.0)$ & $3(4.4)$ & $60(80.0)$ & $101(78.3)$ \\
\hline Psoriatic arthritis & $17(14.2)$ & $32(13.5)^{*}$ & I (3.0) & $0(0.0)$ & $17(22.7)$ & $32(24.8)$ \\
\hline Quan-Charlson score, mean (SD) & $1.0(1.0)$ & $0.7(1.0)^{*}$ & $0.6(I . I)$ & $0.3(1.0)$ & $1.2(0.8)$ & I.I (I.I) \\
\hline $0, \mathrm{n}(\%)$ & $42(35.0)$ & $123(51.9)^{* *}$ & $23(69.7)$ & $59(85.5)$ & $7(9.3)$ & $32(24.8)^{* *}$ \\
\hline $\mathrm{I}-2, \mathrm{n}(\%)$ & $69(57.5)$ & $97(40.9)^{* *}$ & $8(24.2)$ & $7(10.1)$ & $62(82.7)$ & $84(65.1)^{* *}$ \\
\hline $3-4, \mathrm{n}(\%)$ & $8(6.7)$ & $15(6.3)$ & $2(6.1)$ & $2(2.9)$ & $5(6.7)$ & II (8.5) \\
\hline$\geq 5, \mathrm{n}(\%)$ & $\mathrm{I}(0.8)$ & $2(0.8)$ & $0(0.0)$ & $\mathrm{I}(\mathrm{I} .5)$ & $\mathrm{I}(\mathrm{I} .3)$ & $2(1.6)$ \\
\hline Health status score, mean (SD) & $48.0(23.4)$ & $55.4(22.5)^{* *}$ & $51.7(18.5)$ & $53.9(20.4)$ & $45.3(25.5)$ & $51.0(22.6)$ \\
\hline \multicolumn{7}{|l|}{ Provider specialty, n (\%) } \\
\hline Rheumatology & $66(56.4)$ & I I4 (48.5) & $0(0.0)$ & $2(2.9)$ & $62(84.9)$ & $103(80.5)$ \\
\hline Gastroenterology & $30(25.6)$ & $43(18.3)$ & $30(93.8)$ & $43(62.3)^{* * *}$ & $0(0.0)$ & $3(2.3)$ \\
\hline Dermatology & $13(11.1)$ & $30(12.8)$ & $0(0.0)$ & $\mathrm{I}(\mathrm{I} .5)$ & $5(6.9)$ & $5(3.9)$ \\
\hline Internal medicine & I (0.9) & $9(3.8)$ & I (3.I) & I (I.5) & I (I.4) & $8(6.3)$ \\
\hline
\end{tabular}

Notes: *Difference between SDM and non-SDM in category at $P<0.05 ; * * P<0.01 ; * * * P \leq 0.001$. ${ }^{a}$ These conditions are not mutually exclusive and percentages may not sum to 100 .

Abbreviations: IBD, inflammatory bowel disease; PA, psoriatic arthritis; RA, rheumatoid arthritis; SDM, shared decision-making; SD, standard deviation.

non-SDM participants ( $83.2 \%$ vs $72.6 \%$; $P<0.05)$. Specifically, regarding the biologic treatment attributes discussed with their physician, several items were discussed in detail significantly more by SDM participants than by non-SDM participants (Figure 2).

\section{Patient-reported outcome measures}

There was a significant difference in mean (SD) MMAS scores: SDM, 0.17 (0.5) vs non-SDM, 0.41 (0.8); $P=0.001$ (Table 2), which indicates a higher self-reported likelihood of adherence among the SDM patients. Significantly more patients in the non-SDM cohort reported forgetting to take the biologic, being careless about taking it, or stopping it when they feel better. The SDM participants had greater levels of activation, relative to non-SDM participants (PAM scores for SDM vs non-SDM: 66.9 vs 61.6; $P<0.001$; Table 2).
As shown in Figure 3, significantly more SDM participants reported being "extremely satisfied" in terms of overall medication satisfaction $(P<0.05)$, specifically having greater satisfaction with how the medication was administered. Non-SDM participants more frequently reported being only "somewhat satisfied" overall and "not very satisfied" in terms of how quickly the medication reduced symptoms and how the medication was administered.

\section{Claims-based results}

\section{Adherence and persistence}

No significant difference was observed in adherence, as demonstrated by the MPR, by SDM status (Table 3). Nor did percentage of patients persistent differ (with no refill gaps or medication switches) during the therapy maintenance period $(\mathrm{SDM}=45.7 \%$ vs non-SDM $=36.7 \% ; P=0.162$ ). The 


\section{SDM participants}

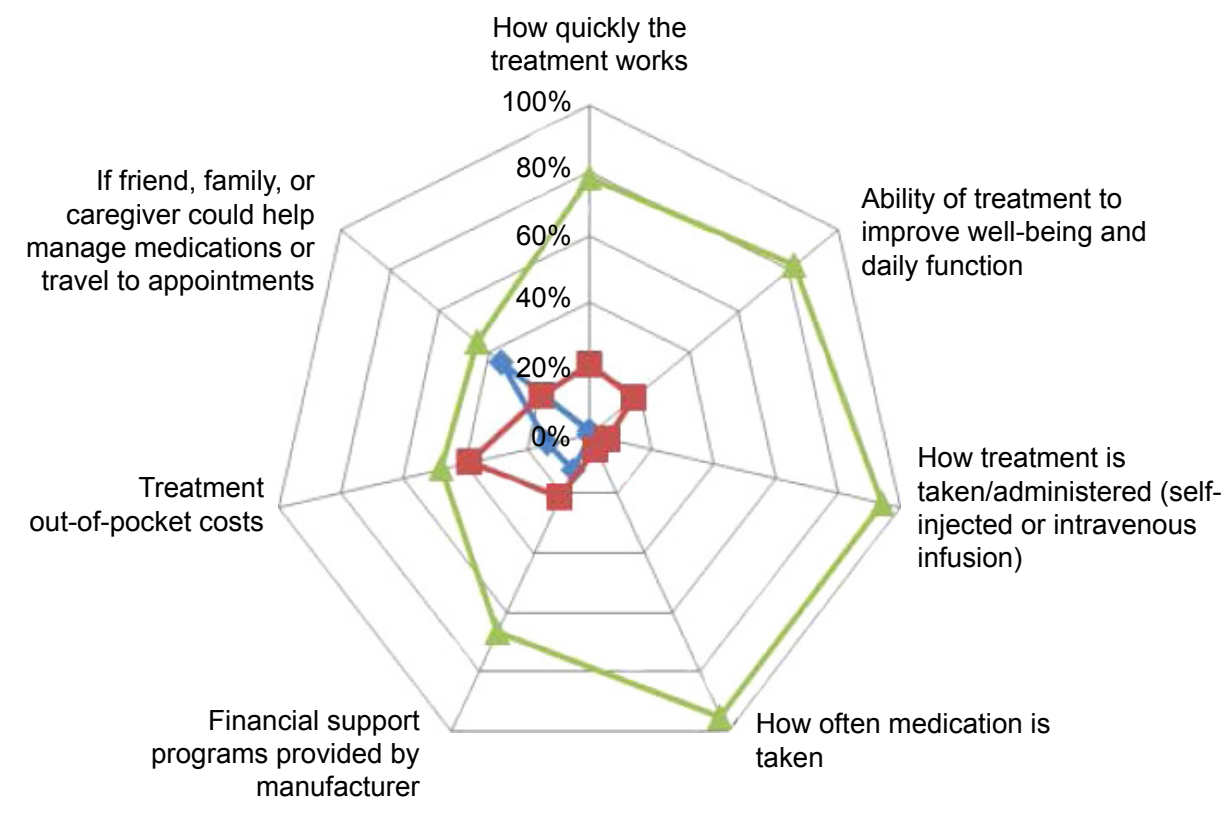

Non-SDM participants

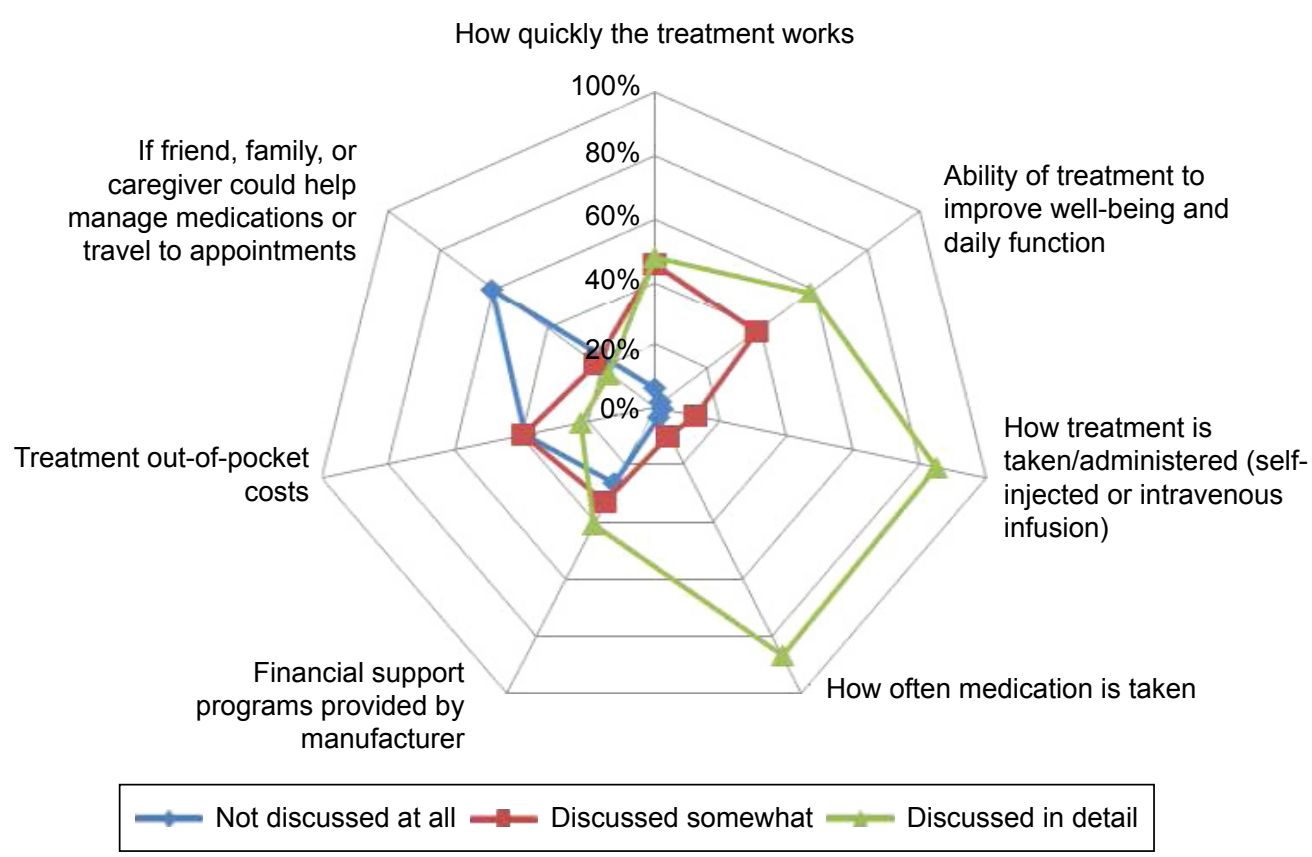

Figure 2 Biologic treatment attributes discussed with physician.

Note: As shown by the larger area within the green lines, significantly $(P<0.05)$ more SDM than non-SDM participants responded "discussed in detail" for all questions. Abbreviation: SDM, shared decision-making.

Table 2 Claims-based results: MMAS and PAM

\begin{tabular}{llll}
\hline & \multicolumn{2}{l}{ Total } & P-value \\
\cline { 2 - 3 } & $\begin{array}{l}\text { SDM } \\
(\mathbf{n}=\mathbf{I} 20)\end{array}$ & $\begin{array}{l}\text { Non-SDM } \\
(\mathbf{n}=\mathbf{2 3 7})\end{array}$ & \\
\hline MMAS score, mean (SD) & $0.17(0.5)$ & $0.4 \mathrm{I}(0.8)$ & $0.00 \mathrm{I}$ \\
PAM score, mean (SD) & $66.9(13.4)$ & $61.6(13.0)$ & $<0.00 \mathrm{I}$ \\
\hline
\end{tabular}

Abbreviations: MMAS, Morisky Medication Adherence Scale; PAM, Patient Activation Measure; SDM, shared decision-making; SD, standard deviation.
MPR also did not differ by SDM status among patients by therapeutic area.

However, the length (days) of persistence in maintenance was greater with SDM (111.2 [30.2] vs overall non-SDM 102.2 [38.1]; $P=0.029$ ). Also, a lower mean number of cumulative days with refill gaps in expected days' supply was observed in the SDM group (17.8 [26.10] days) than in 


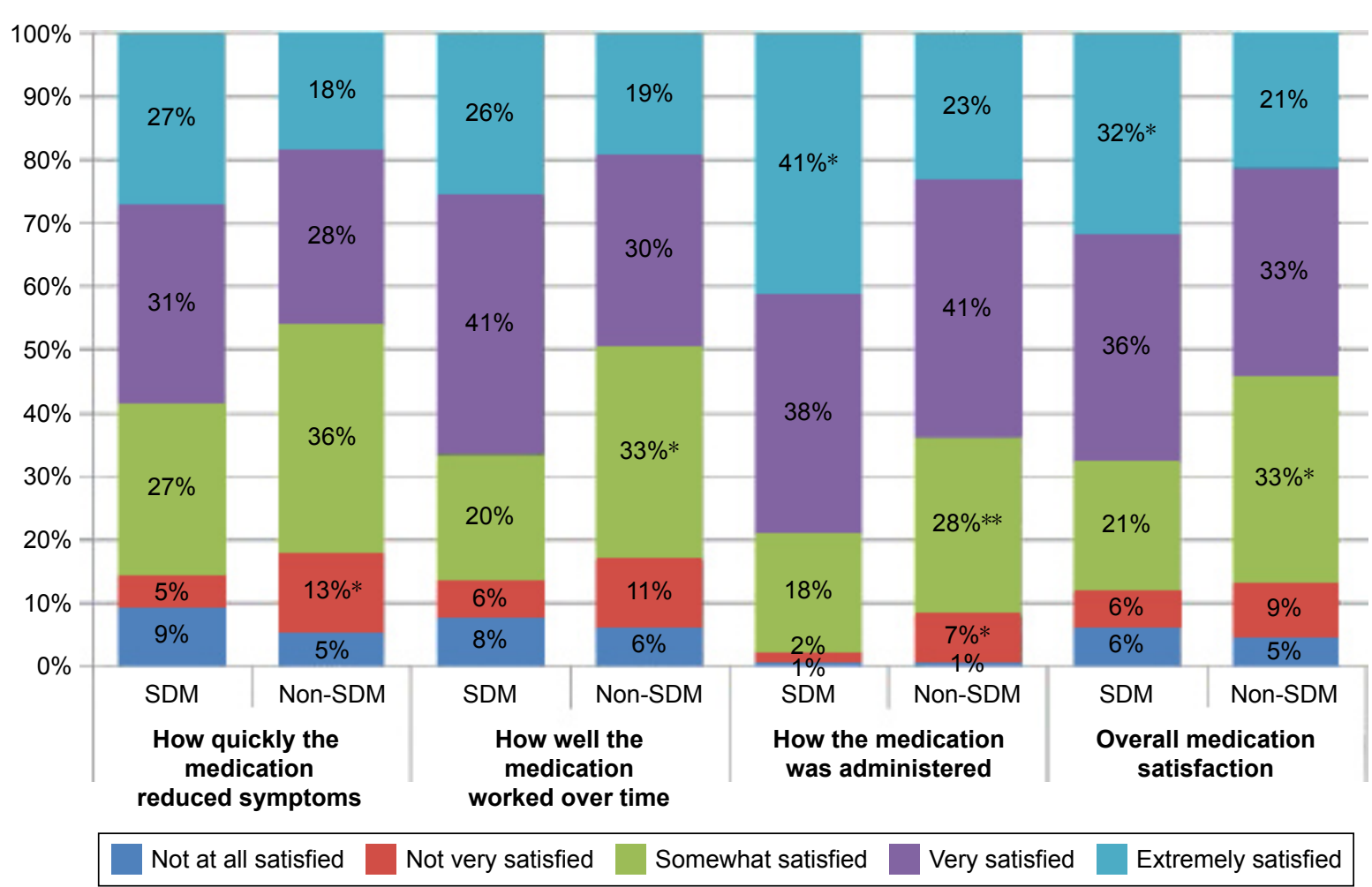

Figure 3 Satisfaction with biologic treatment.

Note: $* P<0.05, * * P<0.075$, comparing SDM and non-SDM patients answering each response identified by color.

Abbreviation: SDM, shared decision-making.

the non-SDM group (26.2 [33.2] days; $P<0.05)$. Although the length of persistence did not differ significantly by SDM status within each therapeutic group, there was a trend $(P=0.060)$ showing reduced persistence among non-SDM participants (99.1 days) vs SDM participants (113.5 days).

\section{Health care costs}

All-cause health care costs are shown in Figure 4. IBD patients who self-reported participating in $\operatorname{SDM}(n=33)$ were more likely than their non-SDM $(n=69)$ counterparts to have lower total all-cause medical costs (mean $\mathrm{SDM}=\$ 9,404$ vs mean non-SDM $=\$ 25,071 ; P=0.003$; in particular,
Inpatient hospital and ambulatory costs) (Figure 4A; $P$-values are noted in the figure above each component). Pharmacy costs trended higher among the SDM patients $(\$ 18,931$ vs $\$ 14,155$ in non-SDM; $P=0.051$ ). In the RA/PA SDM group (Figure 4B), although 6-month total medical costs, inpatient hospital costs, emergency services, and other costs differed from the RA/PA non-SDM group, these differences were not significant.

\section{Discussion}

Despite the growing interest in patient-centered care and SDM, consensus has not yet been reached about how these

Table 3 Claims-based adherence/persistence results, during the maintenance period

\begin{tabular}{|c|c|c|c|c|c|c|c|c|c|}
\hline \multirow[t]{2}{*}{ Measure } & \multicolumn{3}{|l|}{ Total } & \multicolumn{3}{|l|}{ RA/PA } & \multicolumn{3}{|l|}{ IBD } \\
\hline & $\begin{array}{l}\text { SDM } \\
(n=94)\end{array}$ & $\begin{array}{l}\text { Non-SDM } \\
(\mathrm{n}=207)\end{array}$ & $P$-value & $\begin{array}{l}\text { SDM } \\
(n=56)\end{array}$ & $\begin{array}{l}\text { Non-SDM } \\
(n=I I I)\end{array}$ & $P$-value & $\begin{array}{l}\text { SDM } \\
(n=30)\end{array}$ & $\begin{array}{l}\text { Non-SDM } \\
(\mathrm{n}=65)\end{array}$ & $P$-value \\
\hline $\begin{array}{l}\text { MPR, during maintenance, } \\
\text { mean (SD) }\end{array}$ & $0.91(0.12)$ & $0.90(0.14)$ & 0.511 & $0.90(0.13)$ & $0.89(0.15)$ & 0.733 & $0.92(0.12)$ & $0.94(0.08)$ & 0.344 \\
\hline Persistence, days, mean (SD) & $111.2(30.2)$ & $102.2(38.1)$ & 0.029 & $109.6(32.3)$ & $105.5(36.8)$ & 0.477 & II $3.5(27.6)$ & 99.1 (36.7) & 0.060 \\
\hline $\begin{array}{l}\text { Cumulative time with refill } \\
\text { gaps, days, mean (SD) }\end{array}$ & $17.8(26.1)$ & $26.2(33.2)$ & 0.018 & $20.5(26.1)$ & $27.2(32.4)$ & 0.184 & $12.6(25.9)$ & $22.6(33.7)$ & 0.153 \\
\hline
\end{tabular}

Notes: Two aspects contributed to the lower $\mathrm{n}$ values for each group: patients whose index biologic was rituxan were excluded in calculations because this biologic is dosed as needed. Also, patients who discontinued or switched before the maintenance phase were excluded.

Abbreviations: IBD, inflammatory bowel disease; MPR, medication possession ratio; PA, psoriatic arthritis; RA, rheumatoid arthritis; SDM, shared decision-making; $\mathrm{SD}$, standard deviation. 

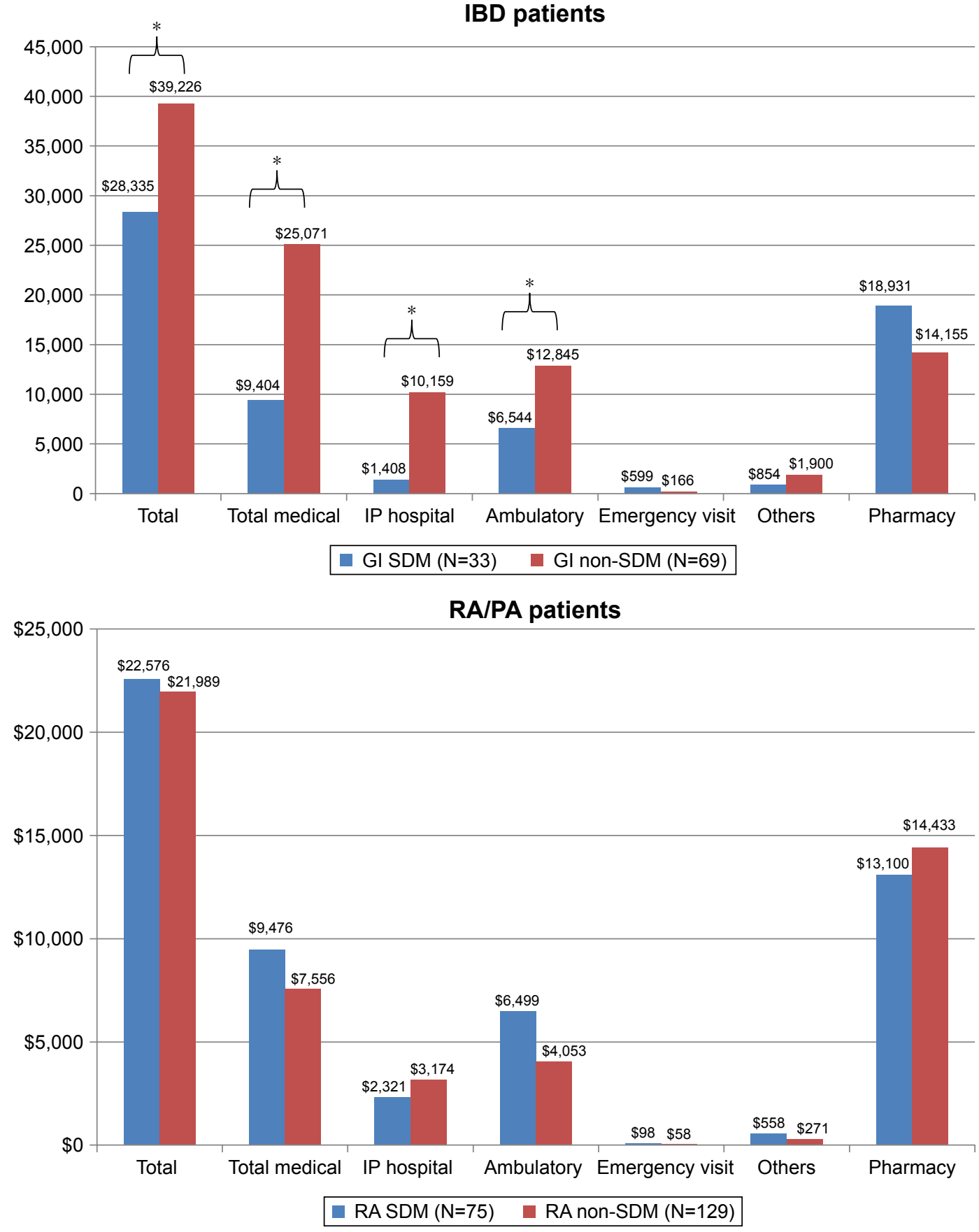

Figure 4 All-cause healthcare costs among IBD and RA/PA groups.

Note: $* p<0.05$.

Abbreviations: IBD, inflammatory bowel disease; PA, psoriatic arthritis; RA, rheumatoid arthritis; SDM, shared decision-making; GI, gastrointestinal; IP, inpatient.

concepts should be put into place. Furthermore, there are potential barriers to implementation of SDM processes, including low health literacy, language barriers, and trust in physicians, as well as lack of awareness of choice. ${ }^{20,23}$ To our knowledge, this is the first study to examine SDM participation in the selection of biologic treatment for autoimmune conditions among a real-world population of patients and to examine future outcomes following treatment initiation.
As the relationship between SDM participation and future outcomes was unknown, our survey collected other possible patient factors, such as activation and treatment satisfaction. Significantly more SDM than non-SDM participants reported being "extremely satisfied" in terms of overall satisfaction, and specifically, with how the drug was administered. Statistically greater proportions of non-SDM participants reported being "somewhat" or "not very" satisfied for the same categories. Among the few SDM-related studies of 
patients with autoimmune diseases, greater satisfaction resulting from SDM has been reported. Siegel et al ${ }^{21}$ found that among patients with IBD, the majority reported increased satisfaction when they participated in SDM. Renzi et al $^{22}$ also found that most patients with PA expressed a preference for being involved in decision-making and that specific types of information on side effects and options were associated with overall patient satisfaction.

SDM participants had greater activation, as measured by the PAM, than did the non-SDM cohort. Little research on the impact of patient activation in the context of treatment of autoimmune disorders with biologics has been done to date. Munson et $\mathrm{al}^{33}$ suggested that using the PAM instrument may be helpful in designing interventions for IBD based upon activation level. Studies have shown that increased patient activation reduces health care utilization and costs in primary care. $^{34,35}$ It is possible that patients having a higher level of activation would be more likely to participate in SDM, or that, regardless of SDM participation, higher PAM scores are associated with greater likelihood of adherence to biologic treatment. In this study, there were no significant differences in MPR, a claims-based measure of adherence, although self-reported likelihood of adherence was greater among the SDM participants. Also, non-SDM participants had more cumulative mean number of days with refill gaps overall. However, 6-month follow-up data may not yet strongly suggest activation or satisfaction as mediators between SDM and outcomes related to adherence or persistence. This may be due to small sample sizes or variability in the time required for a patient to determine either negative or positive results from the use of a particular biologic. However, because this study is the first to analyze outcomes related to SDM in these disease states, future reports on longer study periods are pending.

Finally, at 6-month postinitiation, statistically significant differences in costs were not evident between SDM and non-SDM patients, yet a trend appeared such that non-SDM patients had 2.6 times higher inpatient hospital costs. In a key novel finding, the current study revealed significantly higher costs for the non-SDM patients with IBD disorders - in particular, both inpatient hospital costs (by a factor of 7.2) and ambulatory costs (by a factor of 2.0$)$ were higher $(P<0.05)$. However, given the clinical differences between IBD and RA, differences in the time to observe a response to treatment are expected, and this would result in the observed differences in health care costs. In both SDM and non-SDM patients, pharmaceutical costs were the category representing the greatest component of spending. There are no comparable studies relating SDM to cost outcomes, and a longer time period will provide a better estimate of costs. Continued study of trends observed herein may provide extremely valuable insight into the long-term benefits of SDM.

\section{Limitations}

This study is unique in providing data in support of more than simple associations between SDM and outcomes, yet causality cannot be assigned, and possible limitations should be considered. First, claims data are collected for the purpose of payment, not research, thus the presence of a claim for a filled prescription does not indicate that the medication was consumed as prescribed and medications provided as samples would not be observed. Time lags in availability of claims data are 2-4 months, for the initiation of oral or subcutaneous medications and intravenous medications, respectively; thus the identification approach resulted in oversampling of medications found on pharmacy claims. The presence of a diagnosis code on a medical claim is not a positive proof of disease, as the diagnosis code may be incorrectly coded or included as rule-out criteria rather than actual disease. Certain information that could have an effect on study outcomes is not readily available in claims data, including certain clinical and disease-specific parameters. Also, comparisons to other survey studies are limited by variation in survey instruments, and all surveys are subject to recall bias on the part of the participants. In this study, the overall response rate to the cross-sectional survey was $37.8 \%(n=453)$, but only 306 patients had complete data that could be included in all analyses. Finally, these findings may not be generalizable to those which might be obtained among patients enrolled in a different health care system.

Specific to the conditions studied, the sample size and power needed to detect differences in the follow-up period may not have been adequate, and the length of time required to observe differences in overall health care costs may need to be longer. However, an additional evaluation at 12 months (not shown) did not yield enough sample size for significant findings, due to patients not meeting continuing enrollment criteria.

\section{Conclusion}

Few studies have characterized patients who participate in SDM, and none have previously studied SDM in the context of autoimmune disorders in comparing outcomes after initiating biologic treatments. This study demonstrated that the majority of patients did not engage in SDM prior to treatment selection. However, patients who did engage in SDM discussed more 
options for treatment, and among RA/PA patients, SDM had a significant effect on choice of administration method. Patients who engaged in SDM also demonstrated greater adherence to medication and greater satisfaction compared to patients who did not participate in SDM. Among patients with IBD, SDM also yielded lower total health care costs, in particular for inpatient hospital and ambulatory care, within a 6-month period after initiation of biologic medication. The results of this study support the suggestion of previous studies that SDM can improve adherence and lower health care costs. This study provides a basis for defining SDM cohorts for future studies and suggests associations between SDM and outcomes for patients initiating biologic treatments.

\section{Acknowledgments}

The authors acknowledge contributions from Susan Bolge toward the development of this work. Medical writing support was provided by Caroline Jennermann, of Optum, Inc., funded by Janssen Scientific Affairs, LLC.

\section{Disclosure}

At the time of the study, JHL, MPI, and LE were employees of Janssen Scientific Affairs, LLC, and stockholders in Johnson \& Johnson. PTJ, JCW, and SCR were employees of Optum Inc., and were funded by Janssen Scientific Affairs, LLC, to conduct the study. Their employment was not contingent upon this funding. The authors report no other conflicts of interest in this work.

\section{References}

1. Shafir A, Rosenthal J. Shared Decision Making: Advancing PatientCentered Care through State and Federal Implementation. Washington, DC: National Academy for State Health Policy; 2012. Available from: http://www.nashp.org/sites/default/files/shared.decision.making.report. pdf. Accessed January 24, 2017.

2. Department of Health and Human Services. National Strategy for Quality Improvement in Health Care: Agency-specific Quality Strategic Plans. Bethesda, MD: DHHS; 2011. Available from: https://www.ahrq.gov/ workingforquality/nqs/nqsplans.pdf. Accessed January 24, 2017.

3. Elwyn G, Lloyd A, May C, et al. Collaborative deliberation: a model for patient care. Patient Educ Couns. 2014;97(2):158-164.

4. Elwyn G, Frosch D, Thomson R, et al. Shared decision making: a model for clinical practice. J Gen Intern Med. 2012;27(10):1361-1367.

5. Umar N, Litaker D, Schaarschmidt M-L, et al. Outcomes associated with matching patients' treatment preferences to physicians recommendations: study methodology. BMC Health Serv Res. 2012;12:1.

6. Oshima Lee E, Emanuel EJ. Shared decision making to improve care and reduce costs. $N$ Engl J Med. 2013;368(1):6-8.

7. Arterburn D, Wellman R, Westbrook E, et al. Introducing decision aids at Group Health was linked to sharply lower hip and knee surgery rates and costs. Health Aff. 2012;31(9):2094-2104

8. Kriston L, Scholl I, Hölzel L, Simon D, Loh A, Härter M. The 9-item Shared Decision Making Questionnaire (SDM-Q-9). Development and psychometric properties in a primary care sample. Patient Educ Couns. 2010;80(1):94-99.
9. Giersdorf N, Loh A, Bieber C, et al; Arbeitsgruppe Methoden des BMGS-Förderschwerpunktes Der Patient als Partner im medizinischen Entscheidungsprozess. Development and validation of assessment instruments for shared decision making. Bundesgesundheitsblatt Gesundheitsforschung Gesundheitsschutz. 2004;47(10):969-976. [German].

10. Simon D, Schorr G, Wirtz M, et al. Development and first validation of the shared decision-making questionnaire (SDM-Q). Patient Educ Couns. 2006;63(3):319-327.

11. Simon D, Loh A, Harter M. Measuring (shared) decision-making a review of psychometric instruments. Z Arztl Fortbild Qualitatssich. 2007;101(4):259-267.

12. Simon D, Loh A, Harter M. Die entwicklung und evaluation von interventionen zur förderung partizipativer entscheidungsfindung rahmenkonzept und messinstrumente [Development and evaluation of interventions to support shared decision making - framework and measuring instruments]. Z Med Psychol. 2008;17:149-159. [German].

13. Zampeli E, Vlachoyiannopoulos PG, Tzioufas AG. Treatment of rheumatoid arthritis: unraveling the conundrum. $J$ Autoimmun. 2015;65: $1-18$.

14. Mease PJ. Biologic therapy for psoriatic arthritis. Rheum Dis Clin North Am. 2015;41(4):723-738.

15. Côté-Daigneault J, Bouin M, Lahaie R, Colombel JF, Poitras P. Biologics in inflammatory bowel disease: what are the data? United European Gastroenterol J. 2015;3(5):419-428.

16. Barton JL. Patient preferences and satisfaction in the treatment of rheumatoid arthritis with biologic therapy. Patient Prefer Adherence. 2009:3:335-344.

17. Baars JE, Markus T, Kuipers EJ, van der Woude CJ. Patients' preferences regarding shared decision-making in the treatment of inflammatory bowel disease: results from a patient-empowerment study. Digestion. 2010;81(2):113-119.

18. Mathews AL, Coleska A, Burns PB, Chung KC. The evolution of patient decision-making regarding medical treatment of rheumatoid arthritis. Arthritis Care Res (Hoboken). 2016;68(3):318-324.

19. Conrad S, Hüppe A, Raspe H. Zu welchen themen wünschen patientinnen und patienten mit morbus crohn oder colitis ulcerosa mehr informationen und welche eigene rolle bevorzugen sie bei medizinischen behandlungsentscheidungen? Ergebnisse einer betroffenenbefragung in Deutschland [Preference of patients with inflammatory bowel disease regarding information and shared decision-making: results from a crosssectional survey in Germany]. Z Gastroenterol. 2012;50(4):364-372.

20. Nota I, Drossaert CH, Taal E, van de Laar MA. Arthritis patients' motives for (not) wanting to be involved in medical decision-making and the factors that hinder or promote patient involvement. Clin Rheumatol. 2016;35(5):1225-1235.

21. Siegel CA, Lofland JH, Naim A, et al. Novel statistical approach to determine inflammatory bowel disease: patients' perspectives on shared decision making. Patient. 2016;9(1):79089.

22. Renzi C, Di Pietro C, Tabolli S. Participation, satisfaction and knowledge level of patients with cutaneous psoriasis or psoriatic arthritis. Clin Exp Dermatol. 2011;36(8):885-888.

23. Barton JL, Trupin L, Tonner C, et al. English language proficiency, health literacy, and trust in physician are associated with shared decision-making in rheumatoid arthritis. $J$ Rheumatol. 2014;41(7): 1290-1297.

24. Bewtra M, Johnson FR. Assessing patient preferences for treatment options and process of care in inflammatory bowel disease: a critical review of quantitative data. Patient. 2013;6(4):241-255.

25. Lipstein EA, Dodds CM, Britto MT. Real life clinic visits do not match the ideals of shared decision making. J Pediatr. 2014;165(1):178-183.

26. Ware JE Jr, Sherbourne CD. The MOS 36-item short-form health survey (SF-36): I. Conceptual framework and item selection. Med Care. 1992;30(6):473-483.

27. Hibbard JH, Mahoney ER, Stockard J, Tusler M. Development and testing of a short form of the patient activation measure. Health Serv Res. 2005;40(6):1918-1930. 
28. Morisky DE, Green LW, Levine DM. Concurrent and predictive validity of a self-reported measure of medication adherence. Med Care. 1986;24:67-74.

29. Morisky DE, Malotte CK, Choi P, et al. A patient education program to improve adherence rate with antituberculosis drug regimens. Health Educ Q. 1990;17(3):253-268.

30. Morisky DE, DiMatteo MR. Improving the measurement of self-reported medication nonadherence: final response. J Clin Epidemiol. 2011;64: 258-263.

31. Quan H, Li B, Couris CM, et al. Updating and validating the Charlson comorbidity index and score for risk adjustment in hospital discharge abstracts using data from 6 countries. Am J Epidemiol. 2011;173(6): 676-682.

32. American Association for Public Opinion Research [webpage on the Internet]. Standard Definitions: Final Dispositions and Case Codes and Outcome Rates for Surveys. Deerfield, IL: AAPOR; 2008. Available from http://www.aapor.org/Standards-Ethics/Standard-Definitions-(1). aspx. Accessed January 24, 2017.
33. Munson GW, Wallston KA, Dittus RS, Speroff T, Roumie CL. Activation and perceived expectancies: correlations with health outcomes among veterans with inflammatory bowel disease. J Gen Intern Med. 2009; 24(7):809-815.

34. Hibbard JH, Greene J. What the evidence shows about patient activation: better health outcomes and care experiences; fewer data on costs. Health Aff. 2013;32(2):207-214.

35. Greene J, Hibbard JH. Why does patient activation matter? An examination of the relationships between patient activation and health-related outcomes. J Gen Intern Med. 2012;27(5):520-526.

\section{Publish your work in this journal}

Patient Preference and Adherence is an international, peer-reviewed, open access journal that focuses on the growing importance of patient preference and adherence throughout the therapeutic continuum. Patient satisfaction, acceptability, quality of life, compliance, persistence and their role in developing new therapeutic modalities and compounds to optimize clinical outcomes for existing disease states are major areas of interest for the journal. This journal has been accepted for indexing on PubMed Central. The manuscript management system is completely online and includes a very quick and fair peer-review system, which is all easy to use. Visit http://www dovepress.com/testimonials.php to read real quotes from published authors.

Submit your manuscript here: http://www.dovepress.com/patient-preference-and-adherence-journal 